\title{
A New Approach for Fast Calculation of Sloped Terrace Earthwork Based on GIS in the Hilly Regions
}

\author{
Qingchun Zhang \\ Land Consolidation and Rehabilitation Center, the Ministry of Land and Resources, \\ Beijing Normal University
}

\begin{abstract}
Due to the undulating terrain, earthwork estimation was very difficult in the planning and design of land consolidation projects in the hilly areas. A new approach was proposed to estimate the earthwork of sloped terraces according to map features of planning and design of land consolidation in this paper. It was achieved by applying digital elevation model (DEM) theory and statistical function of the slope with GIS software according to the derived formula. A land consolidation project was chosen as an empirical research example to use the proposed approach in Yangxin County, Hubei Province. Study found that the use of GIS for earthwork estimation of sloped terrace is feasible, the earthwork of different slope range could be estimated quickly according to sloped terrace section (ridge height, ridge slope and the field surface slope after down slope) after getting the area of different slope range using GIS. The approach is simple and fast, with strong practical characteristics. It provided a new idea for earthwork estimation of sloped terrace in hilly area, and improved the efficiency of project planning and design.
\end{abstract}

Keywords: land consolidation, sloped terrace, land leveling.

\section{Introduction}

Terraces were the stepped or sloping section farmlands that were built along the contour in in the mountain areas or hilly areas. Terraces can change the terrain slope, store rainwater, increase soil moisture, and prevent soil erosion, which can achieve water conservation, soil conservation, fertilizer purposes. So terraces have significant ecological and economic benefits to improve agricultural production conditions, promote the steady development and comprehensive management of grain production. "Soil and Water Conservation Law of People's Republic of China" stipulates that the sloping fields below $25^{\circ}$ slopes generally can build terraces to grow crops, and the slope above $25{ }^{\circ}$ should be planted trees and grass. Terraces can be divided into stepped terraces and wave-like terraces according to the section type, and stepped terraces which can be divided into horizontal terraces, sloping terraces, etc.

Land consolidation is effective measures to achieve dynamic balance of total arable land. It is also an important means to improve land quality, promote land use intensively, and protect the ecological environment. Land consolidation is extremely 
important in promoting rural modernization and sustainable economic development. The earthwork amount of land leveling is directly related to the investment of land leveling in land consolidation (Liu etal, 2003). As the large amount of land leveling when sloping fields being built into level terrace, thus, by the level of investment restrictions, many land consolidation projects have carried down slope design, organized into sloping terraces in hilly areas. In hilly areas, due to topography, it is difficult to measure the amount of earthwork (Dong etal, 2004). Currently, some scholars carried out some research for the calculation method of level terrace earthwork. A level terrace earthwork method was proposed through the application of digital elevation model (DEM) theory and GIS software in hilly areas (Liu etal, 2007). The application of " $3 \mathrm{~S}$ " technologies in land leveling has also been explored in depth (Jin etal, 2004; Lu etal, 2003; Chang etal, 2008;Lu etal, 2002)."Comprehensive regulation technical specifications of soil and water conservation -Sloping land Regulation technologies of People's Republic of China " (GB/T16453.1-2008) gives the formula calculation method and calculation of level terrace, but on the sloping terrace does not make provision. It is important that quickly and accurately measuring the amount of earthwork to carry out planning and design, control total investment and allocate the capital. Earthwork calculations for sloping terraces are not the same way, the current method of calculation earthwork mainly included longitudinal method, typical plots method, and direct measuring and calculation method (Fan etal, 2010). These methods are complex, accuracy, and have certain limitations. Therefore, the measure software and methods with a broad user base, simple operation, making full use of existing data sources and estimation results precision were urgently called for in earthwork calculation of slope terrace for land consolidation.

The earthwork calculation method of slope-style terraced is relatively less currently. A fast and accurate earthwork estimation method of slope-style terraced was proposed in this paper, taking a land consolidation project in Sanxi town, Yangxin County, Hubei province as an example. The earthwork was calculated through the application of digital elevation model (DEM) theory and the statistical capabilities of GIS software according to the characteristics of land consolidation planning and design maps, which can provide a reference for earthwork estimation of slope-style terraced in hilly areas.

\section{Study Area}

A low hilly land consolidation project in Sanxi Town, Yangxin County, Hubei Province was taken as an example to introduce the earthwork calculation steps by using this method in this study. Project area is located in east longitude $115^{\circ} 48^{\prime} 22^{\prime \prime}$ $115^{\circ} 49^{\prime} 13^{\prime \prime}$, latitude $29^{\circ} 50^{\prime} 34^{\prime \prime} \sim 29^{\circ} 50^{\prime} 57^{\prime \prime}$, and its construction area is $36.22 \mathrm{hm}^{2}$. Project area has significant low hilly landscape features with undulating terrain, slope degree between $10^{\circ} \sim 15^{\circ}$ and the highest elevation of $75.27 \mathrm{~m}$, the lowest $31.56 \mathrm{~m}$. There are four sections needed to be terraced (Figure 1), with acreage of $2.61 \mathrm{hm}^{2}, 12.02 \mathrm{hm}^{2}, 1.21 \mathrm{hm}^{2}$ and $4.74 \mathrm{hm}^{2}$ respectively. 


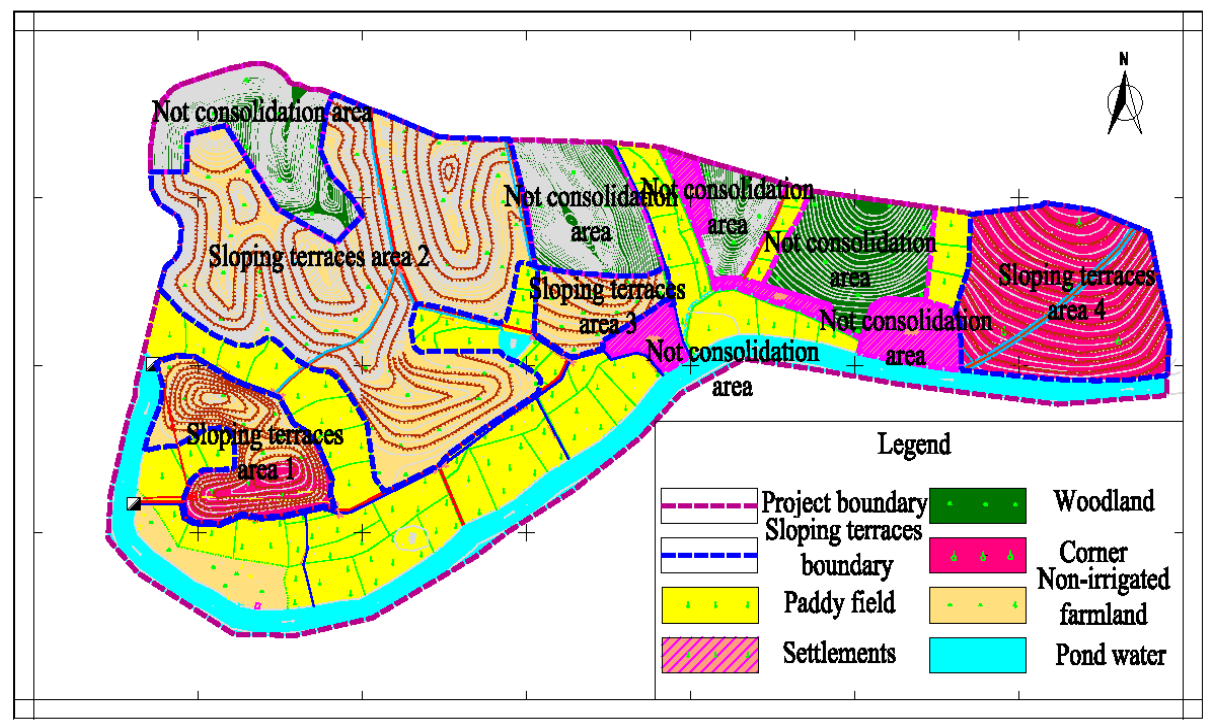

Fig. 1. Land consolidation project area in Sanxi town, Yangxi County, Hubei Province

\section{Calculation Principle of Sloped Terrace Earthwork}

\subsection{Design Elements of Sloping Terrace Section}

Sloping terrace section elements include the original ground slope, the field surface slope after down slope, ridge height, ridge outside slope, net width of field surface, gross width of field surface, land occupation width of ridge and ramp width of field surface (Zheng etal, 2009; Fan etal, 2008). A typical cross-section of slope-style terraces were shown in Figure 2.

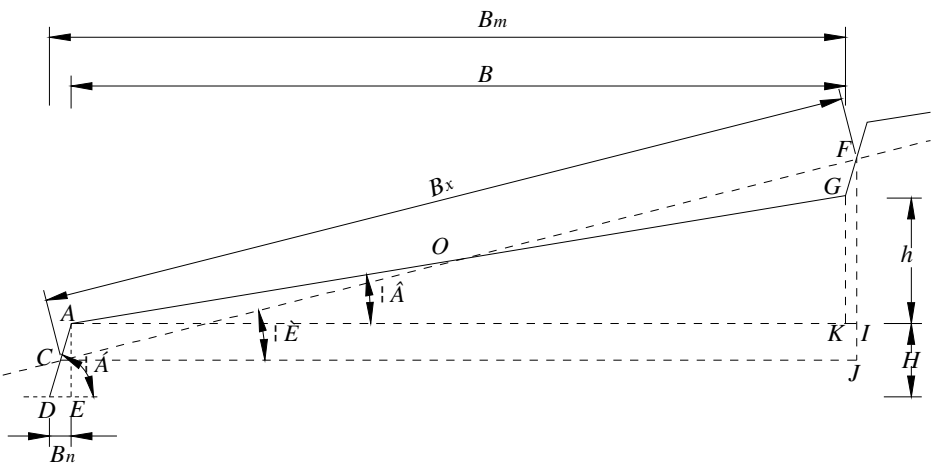

Fig. 2. Section design of sloped terrace 
$\theta$ - The original ground slope, $\left(^{\circ}\right) ; \beta$ - The field surface slope after down slope, $\quad\left(^{\circ}\right) ; \alpha$ Ridge slope, $\left(^{\circ}\right) ; H$-ridge height, $(\mathrm{m})$; $h$-Slope height of Field surface, (m) ; $H^{\prime}$ —Table height, (m) , $H^{\prime}=H+h ; B-$ Clear width of field surface, (m) ; $B_{n}$ - Land Occupation width of ridge, (m) ; $B_{m}-$ Gross width of field surface, $\quad(\mathrm{m})$ ; $B_{x} \_$Ramp width of field surface, (m) 。

\subsection{Earthwork Calculation of Sloped Terrace}

\section{Calculation Principle of Sloping Terraced Earthwork}

According to sloping terrace section design, per unit area $\left(1 \mathrm{hm}^{2}\right)$ sloping terrace earthwork can be calculated by:

$$
V=S_{O A C} \times L
$$

Where $V$ is dig (fill) earthwork of per unit area $\left(1 \mathrm{hm}^{2}\right), \mathrm{m}^{3} ; S_{O A C}$ is cross-section area of triangular $\triangle O A C, \mathrm{~m}^{2} ; L$ is the terraces length of per unit area $\left(1 \mathrm{hm}^{2}\right), \mathrm{m}$.

\section{Cross-Section Area of Triangular $\triangle O A C$}

$$
\begin{aligned}
S_{O A C} & =\frac{1}{2} \times L_{O C} \times L_{A C} \times \sin \angle A C O=\frac{1}{2} \times \frac{H}{2 \sin \alpha} \times \frac{\tan \alpha-\tan \beta}{2 \cos \theta \times \tan \alpha \times(\tan \theta-\tan \beta)} \times H \times \sin (\alpha-\theta) \\
& =\frac{1}{8} \times H^{2} \times \frac{(\tan \alpha-\tan \beta) \times \sin (\alpha-\theta)}{\sin \alpha \times \cos \theta \times \tan \alpha \times(\tan \theta-\tan \beta)}
\end{aligned}
$$

The Terraces Length of Per Unit Area $\left(1 \mathbf{h m}^{2}\right)$

$$
L=\frac{10000}{B}=\frac{10000 \times \tan \mathcal{E} \times(\tan \theta-\tan \beta)}{(\tan \alpha-\tan \theta) \times H}
$$

The Relationship between Table Height and Ridge Height

$$
H^{\prime}=H+h=H+\frac{\tan \beta \times(\tan \alpha-\tan \theta)}{\tan \alpha \times(\tan \theta-\tan \beta)} \times H=\frac{\tan \theta \times(\tan \alpha-\tan \beta)}{\tan \alpha \times(\tan \theta-\tan \beta)} \times H
$$

\section{The Calculation Formula of Sloping Terraced Earthwork}

$$
\begin{aligned}
V & =S_{O A C} \times L=\frac{1}{8} \times H^{2} \times \frac{(\tan \alpha-\tan \beta) \times \sin (\alpha-\theta)}{\sin \alpha \times \cos \theta \times \tan \alpha \times(\tan \theta-\tan \beta)} \times \frac{10000 \times \tan \varepsilon \times(\tan \theta-\tan \beta)}{(\tan \alpha-\tan \theta) \times H} \\
& =1250 \times \frac{\tan \alpha-\tan \beta}{\tan \alpha} \times H=1250 \times \frac{\tan \theta-\tan \beta}{\tan \theta} \times H^{\prime}
\end{aligned}
$$

The results can be found by formula (5): Sloping terraced earthwork is closely related to ridge slope $(\alpha)$, the original field surface slope $(\theta)$, the field surface slope after down slope ( $\beta$ ), ridge height $(H)$, and table height $\left(H^{\prime}\right)$. Just make sure the 
parameters of the three sloping terrace section $\left(\alpha 、 \beta\right.$ and $H$ or $\theta 、 \beta$ and $H^{\prime}$ ) can be formed to determine the amount of earth sloping terrace. In soil characteristics and other factors determined conditions, ground slope is a key factor to determine the parameters $\alpha, \beta$ and $H$.Therefore, if the slope distribution of project area is determined, slope-style terraced earthwork calculation is easy.

\section{Fast Calculation Approach of Sloped Terrace Earthwork Based on GIS in the Hilly Regions}

GIS has slope statistical functions, which provide feasibility for the use of GIS for slope-style terraced earthwork calculation. To estimate the amount of earthwork by

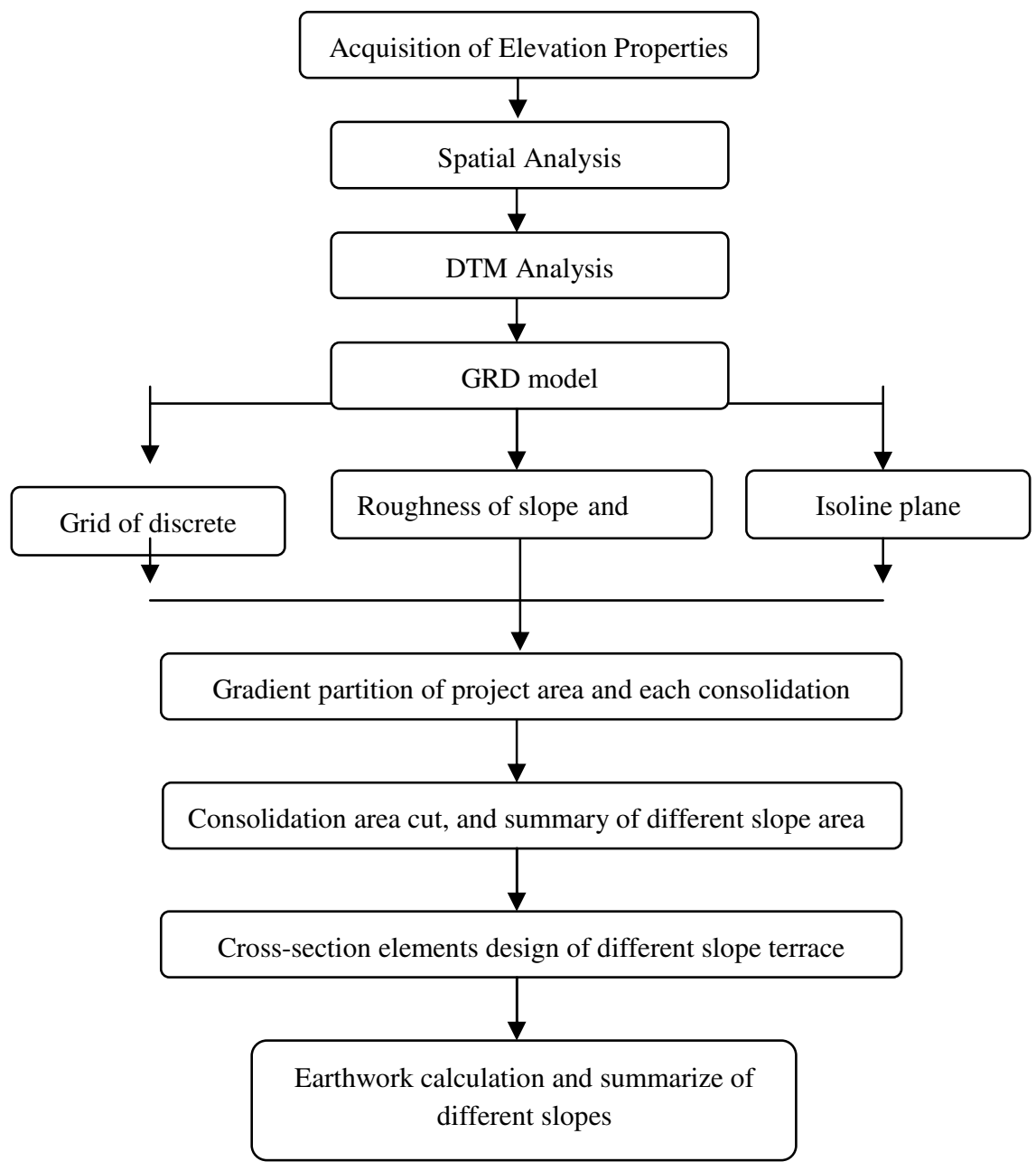

Fig. 3. Fast estimation process of sloping terrace earthwork 
application of GIS technology is a manifestation of GIS software spatial analysis functions. Applying GIS software to measure the amount of earthwork needs the elevation data, including Contour lines, elevation points, etc. General project areas have the latest digital measurement of topographic maps, which provide the basic data for GIS software applications. The basic steps f rapid estimation of sloping terraces earthwork proposed by the use MAPGIS in this study were shown in Figure 3.

\section{$5 \quad$ Case Studies}

According to the basic steps of quick estimation of sloping terraces earthwork by the use of MAPGIS, the land consolidation project area in Sanxi town, Yangxin county, Hubei province was partitioned by slope (Figure 4). The range of different slope range were designed to reduce slope (table 1), then into calculation formula of sloping terraced earthwork, the amount of land consolidation were rapidly measured and summarized (table 1).

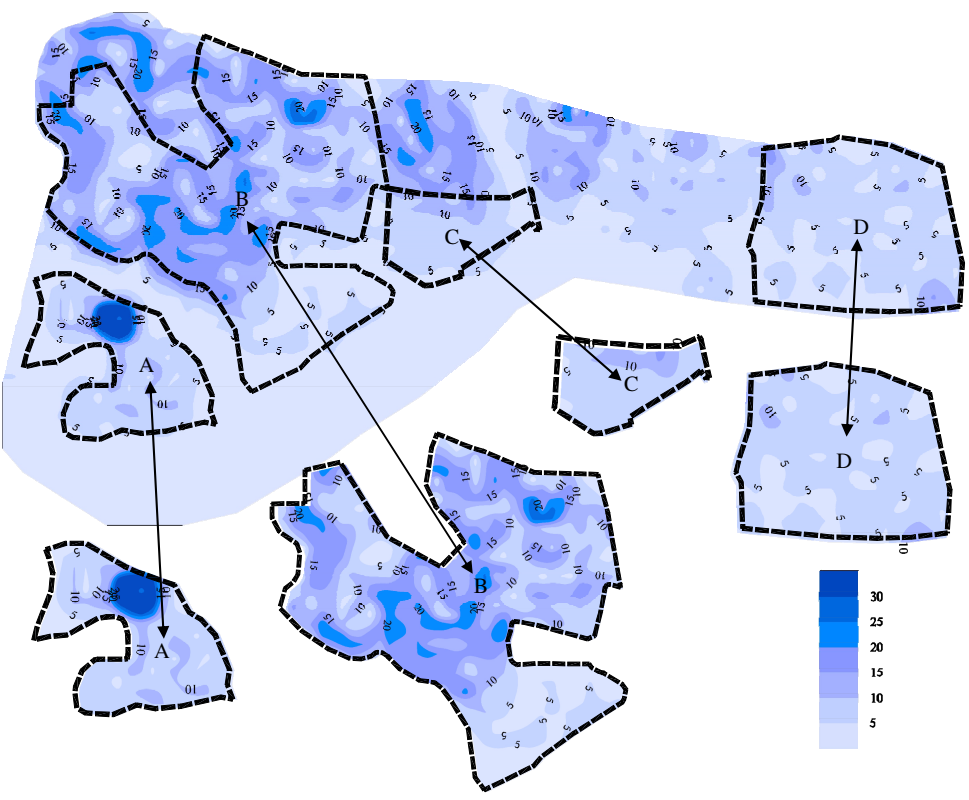

Fig. 4 Slope map of land leveling area

Table 1. Earthwork calculation of sloping terrace land leveling Font sizes of headings.

\begin{tabular}{|c|c|c|c|c|c|c|}
\hline $\begin{array}{c}\text { Consolidating } \\
\text { region }\end{array}$ & Slope & Area & $\begin{array}{l}\text { Ridge } \\
\text { height }\end{array}$ & $\begin{array}{l}\text { Ridge } \\
\text { slope }\end{array}$ & $\begin{array}{c}\text { Field surface } \\
\text { slope after } \\
\text { descending } \\
\text { slope }\end{array}$ & Earthwork \\
\hline & o & $\mathrm{hm}^{2}$ & $\mathrm{~m}$ & o & o & $\mathrm{m}^{3}$ \\
\hline
\end{tabular}


Table 1. (Continued)

\begin{tabular}{|c|c|c|c|c|c|c|}
\hline \multirow{7}{*}{$\begin{array}{l}\text { Consolidating } \\
\text { region } 1\end{array}$} & $0-5$ & 0.34 & 0.8 & 85 & 0.0 & 341.65 \\
\hline & $5-10$ & 1.57 & 1.2 & 80 & 5.0 & 2322.57 \\
\hline & $10-15$ & 0.36 & 1.8 & 75 & 10.0 & 772.84 \\
\hline & $15-20$ & 0.06 & 2.2 & 70 & 10.0 & 148.89 \\
\hline & $20-25$ & 0.05 & 2.4 & 65 & 10.0 & 133.33 \\
\hline & $>25$ & 0.23 & & & & 0.00 \\
\hline & Total & 2.61 & & & & 3719.29 \\
\hline \multirow{7}{*}{$\begin{array}{c}\text { Consolidating } \\
\text { region } 2\end{array}$} & $0-5$ & 1.59 & 0.8 & 85 & 0.0 & 1590.04 \\
\hline & $5-10$ & 3.36 & 1.2 & 80 & 5.0 & 4966.74 \\
\hline & $10-15$ & 3.23 & 1.8 & 75 & 10.0 & 6929.53 \\
\hline & $15-20$ & 3.02 & 2.2 & 70 & 10.0 & 7776.79 \\
\hline & $20-25$ & 0.76 & 2.4 & 65 & 10.0 & 2085.71 \\
\hline & $>25$ & 0.06 & & & & 0.00 \\
\hline & Total & 12.02 & & & & 23348.81 \\
\hline \multirow{7}{*}{$\begin{array}{l}\text { Consolidating } \\
\text { region } 3\end{array}$} & $0-5$ & 0.04 & 0.8 & 85 & 0.0 & 40.40 \\
\hline & $5-10$ & 0.97 & 1.2 & 80 & 5.0 & 1431.40 \\
\hline & $10-15$ & 0.19 & 1.8 & 75 & 10.0 & 405.93 \\
\hline & $15-20$ & 0.01 & 2.2 & 70 & 10.0 & 23.41 \\
\hline & $20-25$ & 0.00 & 2.4 & 65 & 10.0 & 0.00 \\
\hline & $>25$ & 0.00 & & & & 0.00 \\
\hline & Total & 1.21 & & & & 1901.14 \\
\hline \multirow{7}{*}{$\begin{array}{l}\text { Consolidating } \\
\text { region } 4\end{array}$} & $0-5$ & 1.17 & 0.8 & 85 & 0.0 & 1167.78 \\
\hline & $5-10$ & 3.39 & 1.2 & 80 & 5.0 & 5013.83 \\
\hline & $10-15$ & 0.17 & 1.8 & 75 & 10.0 & 371.60 \\
\hline & $15-20$ & 0.00 & 2.2 & 70 & 10.0 & 0.96 \\
\hline & $20-25$ & 0.00 & 2.4 & 65 & 10.0 & 0.00 \\
\hline & $>25$ & 0.00 & & & & 0.00 \\
\hline & Total & 4.74 & & & & 6554.17 \\
\hline
\end{tabular}

\section{Conclusions}

This study proposes a new calculation method of terraced earthwork in hilly area, and this method is applied to the actual project area. Through research the following conclusions can be reached: 
(1) Sloping terraced earthwork is closely related to ridge slope $(\alpha)$, the original field surface slope $(\theta)$, the field surface slope after down slope $(\beta)$, ridge height ( $H$ ), and table height $\left(H^{\prime}\right)$.Just make sure the parameters of the three sloping terrace section $\left(\alpha 、 \beta\right.$ and $H$ or $\theta 、 \beta$ and $H^{\prime}$ ) can be formed to determine the amount of earth sloping terrace. Use of GIS for slope-style terraced earthwork calculation is feasible.

(2) Earthwork calculation principles of the proposed method are clear, and easily measured. The earthwork of different slope range could be estimated quickly according to sloped terrace section (ridge height, ridge slope and the field surface slope after down slope) after getting the area of different slope range using GIS. The workload of earthwork calculation was greatly reduced.

(3) The approach is simple and fast, with strong practical characteristics. It provides a new idea for earthwork estimation of sloped terrace in hilly area, and improves the efficiency of project planning and design.

\section{References}

1. Liu, C., Du, L.: Application of Arcview for calculating earthwork in land consolidation project. Transactions of the CSAE 19(2), 224-227 (2003)

2. Dong, J., Zhang, A.: Practice in land consolidation in hilly regions of south china: case study of shangsi county, guangxi zhuang autonomous region. China Land Science 18(2), 53-55 (2004)

3. Liu, N., Yun, W., Lei, T.: Method for fast estimation of terrace earthwork in the hilly regions and its application. Transactions of the CSAE 23(4), 47-51 (2007)

4. Jin, X., Li, H., Zhou, Y., et al.: Assistant decision making for DEM-based land readjustment project in hills and mountainous areas. China Land Science 18(1), 39-44 (2004)

5. Lu, C., Wu, C., Wang, F., et al.: Application of GIS technology in earthwork calculation and allocation of farmland consolidation. Transactions of the CSAE 19(6), 289-292 (2003)

6. Chang, L., Zhang, W., Li, C., et al.: Research of some problems in land consolidation based on GIS technology. Journal of Southwest Agricultural University (Social Science Edition) 6(3), 9-12 (2008)

7. Bao, H., Wu, C., Ye, Y., et al.: Dimension design of farmland and application of GPSGIS-RS technology to land consolidation. Transactions of the CSAE 18(1), 167-172 (2002)

8. Fan, Y., Luo, Y., Wei, C.: On level terrace engineering design of slope land in the hilly and mountainous, southwestern China. Journal of Mountain Science 28(5), 560-565 (2010)

9. Zheng, C., Qiu, D., Tian, S.: A Formula Deduced for the Calculation of Earthwork Volume of Sloped Terrace in Hilly Area. Journal of Southwest University (Natural Science Edition) 31(1), 173-178 (2009)

10. Zhou, W., Liu, X., Yang, C.: Study on land consolidation status in the hilly and mountainous region of southwest China. Journal of Southwest China Normal University (Natural Science Edition) 33(2), 104-109 (2008) 